\title{
Delineation of Prior Austenite Grain Boundaries in a Low-Alloy High-Performance Steel
}

\author{
V. Sinha ${ }^{1,2}$ - E. J. Payton ${ }^{1}$ - M. Gonzales ${ }^{1}$ - R. A. Abrahams ${ }^{3}$ B. S. Song ${ }^{1}$
}

Received: 8 August 2017/Revised: 28 September 2017/Accepted: 8 October 2017/Published online: 17 November 2017

(C) Springer Science+Business Media, LLC and ASM International 2017

\begin{abstract}
Characterization of prior austenite grain size is important for understanding the microstructure-property relationships in steels. The prior austenite grain size plays an important role in defining the microstructural scale of low-temperature phases and the mechanical properties (e.g., strength, ductility, fracture toughness, etc.) of steels in the final product form. Moreover, in several failure analyses, the cracks are observed to propagate along the prior austenite grain boundaries (PAGBs). The delineation of PAGBs in steels of new composition can be quite challenging, as the response to a particular etching protocol is very sensitive to the chemical composition of steel. The objective of this study was to establish a methodology to delineate PAGBs in AF9628, a newly developed low-alloy high-performance steel. Several different etchants and etching techniques from the literature were evaluated. These methods were unsuccessful or had limited success in revealing PAGBs in AF9628. However, swab etching with a solution of $100 \mathrm{ml}$ saturated aqueous picric acid and $0.5 \mathrm{~g}$ sodium dodecyl benzene sulfonate worked remarkably well for delineating the PAGBs in this steel. This etchant was found to have high selectivity, revealing
\end{abstract}

V. Sinha

vikas.sinha.1.ctr@us.af.mil

1 Air Force Research Laboratory, Materials and Manufacturing Directorate, AFRL/RXCM, Wright-Patterson Air Force Base, OH 45433, USA

2 UES, Inc, 4401 Dayton-Xenia Road, Dayton, OH 45432, USA

3 Air Force Research Laboratory, Munitions Directorate, AFRL/RWMWS, Eglin Air Force Base, FL 32542, USA
PAGBs preferentially over packet, block, and sub-block boundaries.

Keywords Steel · Etching · Prior austenite grain boundary

\section{Introduction}

Prior austenite grain size dictates the size of several other microstructural features in steels [1]. For example, the martensitic packet size is reported to be intimately related to the prior austenite grain size [2]. Moreover, the creep cracks are reported to preferentially propagate along prior austenite grain boundaries (PAGBs) [3]. Therefore, the delineation of PAGBs and the determination of prior austenite grain size are important for an improved understanding of the microstructure-property relationships in steels.

The McQuaid-Ehn test is an effective method to delineate PAGBs in steels with less than $0.25 \%$ carbon. It consists of carburizing specimens at $927 \pm 14^{\circ} \mathrm{C}$ for $8 \mathrm{~h}$ or until an $\sim 1.27-\mathrm{mm}$-thick hypereutectoid case is obtained, then slow (furnace) cooling to a temperature below the lower critical to precipitate cementite at the PAGBs of the hypereutectoid zone of the case, and subsequently sectioning, polishing and suitably etching to reveal the PAGBs of the hypereutectoid case [4]. As the McQuaid-Ehn test was designed for evaluating the grain growth characteristics of steels intended for carburizing applications, it may not be a suitable method in cases where the austenitizing temperature and time of interest are not adequate to form a hypereutectoid case. Furthermore, in investigations such as failure analyses of steels, it is desirable to preserve the original microstructural state, which can be altered by the carburizing heat treatment employed as part of the 
McQuaid-Ehn test. Under these circumstances, techniques such as chemical etching may be more appropriate, as they do not require exposure of steel to high temperatures.

Delineation of PAGBs with chemical etching can be quite challenging, as the response to a particular etchant is very sensitive to the chemical composition of steel. One of the first etchants used for determining prior austenite grain size was the solution containing $1 \mathrm{~g}$ picric acid, $5 \mathrm{ml} \mathrm{HCl}$, and $100 \mathrm{ml}$ ethanol, which was developed by Vilella [5, 6]. Nital is reported to successfully reveal PAGBs in hardened and tool steels [7]. Several etchants containing $\mathrm{FeCl}_{3}$ are reported to be successful in revealing PAGBs in different steels [5, 8, 9]. Swarr and Krauss reported success with a solution of $80 \mathrm{ml} \mathrm{H} \mathrm{H}_{2} \mathrm{O}, 28 \mathrm{ml}$ oxalic acid (10\%), and $4 \mathrm{ml}$ $\mathrm{H}_{2} \mathrm{O}_{2}$ in revealing PAGBs in a high purity $\mathrm{Fe}-0.2 \mathrm{C}$ alloy $[2,10]$. The PAGBs in an Fe-1.22C alloy were revealed by etching in a boiling solution of $25 \mathrm{~g} \mathrm{NaOH}, 2 \mathrm{~g}$ picric acid, and $100 \mathrm{ml} \mathrm{H}_{2} \mathrm{O}$ for $15 \mathrm{~min}$, followed by etching lightly in nital [10]. An etchant containing saturated aqueous picric acid and $0.5 \%$ sodium alkylsulfonate (a wetting agent) was first reported by Bechet and Beaujard [11] to delineate PAGBs and is widely considered to be the single most effective etchant for revealing PAGBs [5]. However, the Bechet-Beaujard etching solution has notable difficulties revealing PAGBs for certain steel compositions. Low-carbon alloy steels are reported to be difficult to etch with Bechet-Beaujard etchant [12]. Zhang and Guo [12] have reported that the Bechet-Beaujard etchant does not work if the phosphorus content of the steel is very low.

In AISI 4340 steel, which did not respond well to Bechet-Beaujard etchant, an addition of small amount (a few drops to a few $\mathrm{ml}$ per $100 \mathrm{ml}$ of etchant) of $\mathrm{HCl}$ was reported to successfully delineate the PAGBs [5]. Krauss also reported that etching with an aqueous solution saturated with picric acid and containing sodium tridecylbenzene sulfonate with small additions of $\mathrm{HCl}$ was one of the most effective techniques to reveal PAGBs in hardened steels [10]. A solution containing $10 \mathrm{~g} \mathrm{CrO}_{3}, 50 \mathrm{~g} \mathrm{NaOH}$, $1.5 \mathrm{~g}$ picric acid, and $100 \mathrm{ml}$ distilled water was also reported to provide significantly improved results in comparison with the Bechet-Beaujard solution, including a wider range of applicability with respect to steel compositions, heat treatments, and microstructures [12].

Prior studies report immersion etching in a suitable etchant as an effective method to delineate PAGBs in steels [12, 13]. However, swab etching with a heated etchant (saturated aqueous picric acid with small amounts of $\mathrm{HCl}$ and a wetting agent) was reported to be effective for a heat treated AISI 4340 steel, which was marginally etched by immersion etching at room temperature in the same etchant (i.e., saturated aqueous picric acid with small amounts of $\mathrm{HCl}$ and a wetting agent) [13].
Effective etchants preferentially attack the PAGBs, although light etching of intragranular microstructural features is not uncommon. To remove the lightly etched intragranular features (while retaining the more deeply etched PAGBs) in the micrographs, a light repolish/backpolish is often needed $[5,10,13]$. To get the best possible results, several back-polish and etch cycles may be needed in many instances [5].

AF9628 is a recently developed low-alloy high-performance steel [14]. The present study was undertaken to assess the efficacy of different etchants to delineate PAGBs in this alloy. For several reagents, etching with and without subsequent back-polishing (once or multiple times) was carried out to better reveal the PAGBs. The effectiveness of different etching methods (e.g., immersion etch and swab etch) for AF9628 steel was also evaluated.

\section{Materials and Methods}

The AF9628 steel characterized in this study was provided as a bar of $101.6 \mathrm{~mm}$ diameter. The measured composition is shown in Table I. The carbon and sulfur contents were determined using combustion infrared detection, and the other elements were measured by glow discharge atomic emission spectrometry. An $\sim 25.4-\mathrm{mm}$-thick slice was sectioned from the as-received bar by band saw and then sectioned by wire electrical discharge machining (EDM) into four quarter-round blocks for heat treatment. One block was subjected to a three-step heat treatment cycle as follows: (i) $1010^{\circ} \mathrm{C} / 1 \mathrm{~h} /$ air cool, (ii) $677^{\circ} \mathrm{C} / 1 \mathrm{~h} /$ air cool, and (iii) $1010^{\circ} \mathrm{C} / 1 \mathrm{~h} /$ water quench.

The specimens were cut from the heat treated block of steel and were at least $5 \mathrm{~mm}$ from the outer surfaces of the block to avoid the possibility of any decarburized layer affecting the results. The sectioned specimens were subsequently prepared via standard metallographic procedures, which consisted of grinding on $\mathrm{SiC}$ paper up to $30 \mu \mathrm{m}$ finish, polishing with diamond paste up to $1 \mu \mathrm{m}$ finish, and final polishing to a $0.05 \mu \mathrm{m}$ finish using colloidal alumina in a vibratory polisher.

The specimens were etched with several different etchants and using different etching techniques. The variation in etching techniques included immersion etching, immersion etching in an ultrasonic cleaner, and swab etching. Etching with several solutions was followed by low-pressure back-polishing with colloidal alumina. The back-polish was carried out for 10-15 s, and the specimens were examined in an optical microscope to assess if the intragranular features in the microstructure were removed. If the intragranular features were not removed, the backpolishing was continued and the microstructure was examined at the intervals of $\sim 15 \mathrm{~s}$. The total back- 
Table I Chemical composition (wt\%) of AF9628 steel

\begin{tabular}{lllllllllllll}
\hline $\mathrm{C}$ & $\mathrm{Mn}$ & $\mathrm{Si}$ & $\mathrm{P}$ & $\mathrm{S}$ & $\mathrm{Cr}$ & $\mathrm{Ni}$ & $\mathrm{Mo}$ & $\mathrm{Cu}$ & $\mathrm{V}$ & $\mathrm{N}$ & $\mathrm{O}$ & $\mathrm{Fe}$ \\
\hline 0.255 & 0.71 & 0.91 & 0.0125 & 0.0085 & 2.635 & 0.94 & 0.905 & 0.08 & 0.09 & 0.0068 & 0.0025 & Bal. \\
\hline
\end{tabular}

Table II Details of etching solutions and procedures

\begin{tabular}{|c|c|c|}
\hline Figure no. & Etchant & Etching method \\
\hline 1 & $2 \%$ nital & Swab etch for $5 \mathrm{~min}$ \\
\hline 2 & $\begin{array}{l}1 \mathrm{~g} \text { picric acid, } 5 \mathrm{ml} \mathrm{HCl} \text {, and } 100 \mathrm{ml} \text { ethanol } \\
\text { (Vilella's reagent) }\end{array}$ & Immersion etch for $5 \mathrm{~s}$ \\
\hline 3 & $2 \%$ aqueous $\mathrm{FeCl}_{3}$ & Immersion etch for $5 \mathrm{~s}$ \\
\hline 4 & $\begin{array}{l}10 \mathrm{~g} \mathrm{CrO}_{3}, 50 \mathrm{~g} \mathrm{NaOH}, 1.5 \mathrm{~g} \text { picric acid, and } \\
100 \mathrm{ml} \text { distilled water }\end{array}$ & Immersion etch at $120^{\circ} \mathrm{C}$, followed by back-polish $(1 \times)$ \\
\hline 5 & $2 \%$ aqueous $\mathrm{FeCl}_{3}$ & Immersion etch for $5 \mathrm{~s}$, followed by back-polish $(3 \times)$ \\
\hline 6 & $\begin{array}{l}1 \mathrm{~g} \text { picric acid, } 5 \mathrm{ml} \mathrm{HCl} \text {, and } 100 \mathrm{ml} \text { ethanol } \\
\text { (Vilella's reagent) }\end{array}$ & $\begin{array}{l}\text { Immersion etch for } 5 \mathrm{~s} \text {, followed by back-polish }(1 \times) \text {. } \\
\text { Thereafter, immersion etch for } 10 \mathrm{~s} \text {, followed by back- } \\
\text { polish }(2 \times)\end{array}$ \\
\hline 7 & $\begin{array}{l}100 \mathrm{ml} \text { saturated aqueous picric acid and } \\
0.5 \mathrm{~g} \text { wetting agent }{ }^{\mathrm{a}}\end{array}$ & $\begin{array}{l}\text { Immersion etch in ultrasonic cleaner for } 7 \mathrm{~min} \text {, followed by } \\
\text { back-polish }(1 \times)\end{array}$ \\
\hline 8 & $\begin{array}{l}100 \mathrm{ml} \text { saturated aqueous picric acid and } 1 \mathrm{~g} \\
\text { wetting agent }^{\mathrm{a}}\end{array}$ & $\begin{array}{l}\text { Immersion etch in ultrasonic cleaner for } 5 \mathrm{~min} \text {, followed by } \\
\text { back-polish }(1 \times) \text {. Thereafter, immersion etch in } \\
\text { ultrasonic cleaner for another } 2 \text { min, followed by back- } \\
\text { polish }(1 \times)\end{array}$ \\
\hline 9 & $\begin{array}{l}100 \mathrm{ml} \text { saturated aqueous picric acid, } 0.5 \mathrm{~g} \\
\text { wetting agent }^{\mathrm{a}} \text {, and } 0.3 \mathrm{ml} \mathrm{HCl}\end{array}$ & $\begin{array}{l}\text { Immersion etch in ultrasonic cleaner for } 3 \text { min. No back- } \\
\text { polish }^{\text {b }}\end{array}$ \\
\hline 10 & $\begin{array}{l}100 \mathrm{ml} \text { saturated aqueous picric acid, } 0.5 \mathrm{~g} \\
\text { wetting agent }^{\mathrm{a}} \text {, and } 0.3 \mathrm{ml} \mathrm{HCl}\end{array}$ & $\begin{array}{l}\text { Immersion etch in ultrasonic cleaner for } 7 \mathrm{~min} \text {, followed by } \\
\text { back-polish for } \sim 1 \min (1 \times)\end{array}$ \\
\hline 11 and 12 & $\begin{array}{l}100 \mathrm{ml} \text { saturated aqueous picric acid and } \\
0.5 \mathrm{~g} \text { wetting agent } \mathrm{t}^{\mathrm{a}}\end{array}$ & Swab etch for $\sim 3$ min \\
\hline
\end{tabular}

${ }^{\text {a }}$ sodium dodecyl benzene sulfonate

${ }^{\mathrm{b}} 15$ second back-polish was observed to remove most of the features

polishing time was $\sim 15 \mathrm{~s}$ in lightly etched specimens, and it was as high as $\sim 3$ min in a few deeply etched specimens. If the back-polish removed both the intragranular features and the PAGBs simultaneously, the specimens were etched again. The etching/back-polishing sequence was repeated multiple times in a few experiments. The chemistry of etchants and the details of etching techniques are provided in Table II.

The microstructures were examined with an optical microscope. Both polarized light microscopy and bright field optical microscopy techniques were assessed to determine which technique provided better delineation of PAGBs, which appeared to depend on the specific etching methodology used.

The etching conditions were optimized via observations with the optical microscope. The specimen etched with the optimized condition was also examined in a scanning electron microscope (SEM) using a secondary electron detector.

\section{Results}

The etching with $2 \%$ nital shows that the microstructure consists of lath martensite (Fig. 1). Next, a solution of $80 \mathrm{ml} \mathrm{H}_{2} \mathrm{O}, 28 \mathrm{ml}$ oxalic acid (10\%), and $4 \mathrm{ml} \mathrm{H}_{2} \mathrm{O}_{2}$ was used, which was reported to reveal PAGBs in Fe-0.2C alloy $[2,10]$. However, this etchant did not etch the heat treated AF9628 steel at all.

The immersion in Vilella's reagent (i.e., $1 \mathrm{~g}$ picric acid, $5 \mathrm{ml} \mathrm{HCl}$, and $100 \mathrm{ml}$ ethanol) etched the specimen in relatively short time. However, Vilella's reagent also revealed the martensitic blocks and packets, and did not preferentially attack the PAGBs (Fig. 2). Immersion etching with $2 \%$ aqueous $\mathrm{FeCl}_{3}$ also etched the specimen in relatively short time. This etchant revealed the martensitic blocks and not the PAGBs (Fig. 3).

Next, the specimens were immersion etched with $10 \mathrm{~g}$ $\mathrm{CrO}_{3}, 50 \mathrm{~g} \mathrm{NaOH}, 1.5 \mathrm{~g}$ picric acid, and $100 \mathrm{ml}$ distilled water. This etchant was heated to $120^{\circ} \mathrm{C}$ prior to immersion of specimens. This etchant and etching technique was reported to delineate PAGBs in steels with a wide range of 

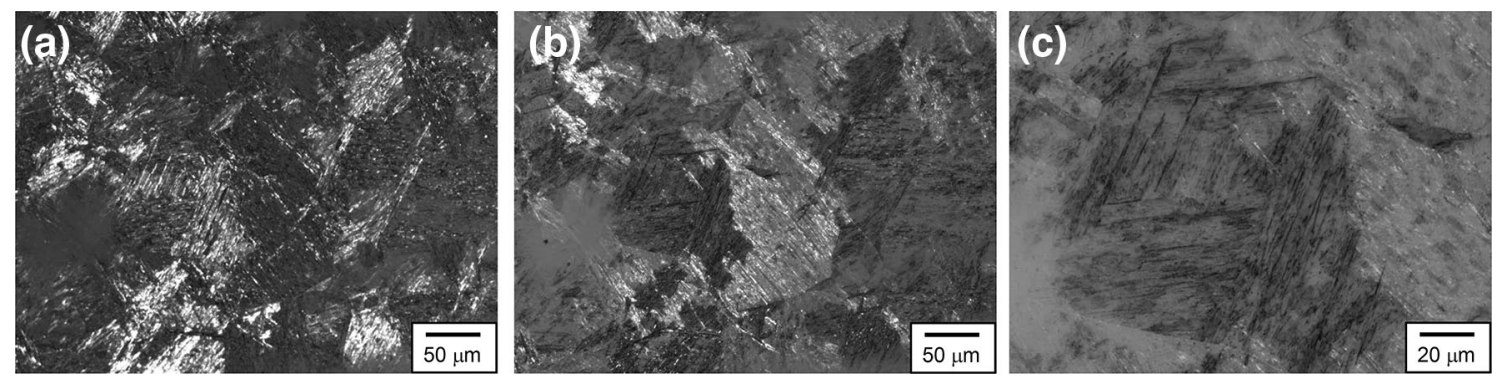

Fig. 1 Polarized light micrographs after swab etching with $2 \%$ nital for $5 \mathrm{~min}$. (a, b) show the same area, with different analyzer settings. (c) Higher magnification image with the analyzer setting same as in (b)
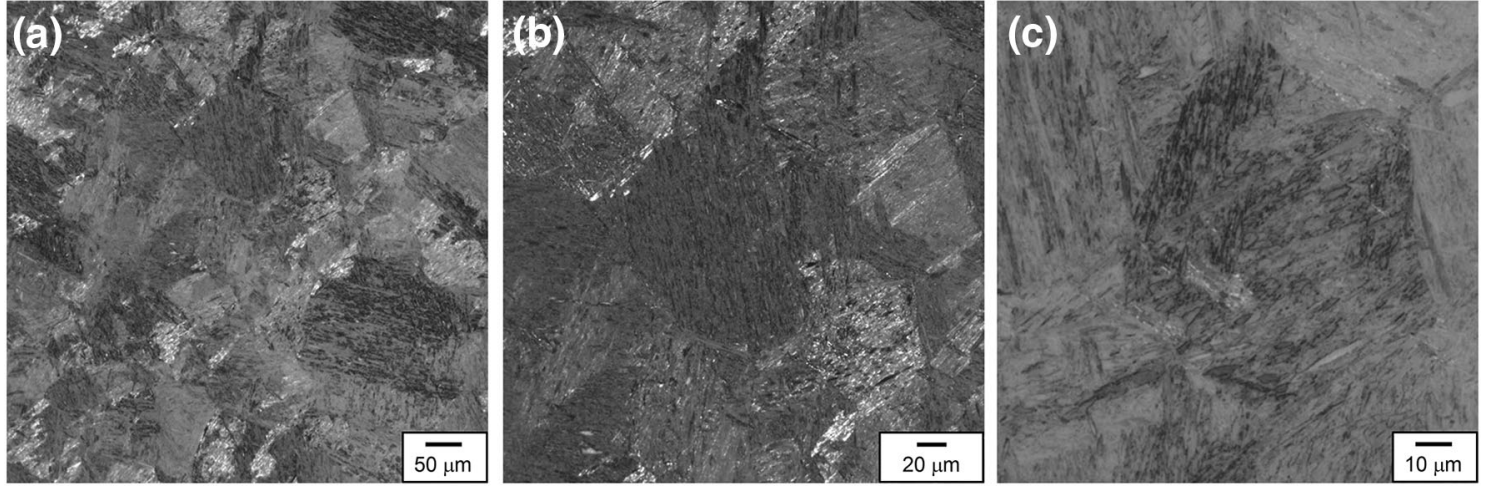

Fig. 2 Polarized light micrographs after immersion etching with Vilella's reagent $(1 \mathrm{~g}$ picric acid, $5 \mathrm{ml} \mathrm{HCl}$, and $100 \mathrm{ml}$ ethanol) for $5 \mathrm{~s}$
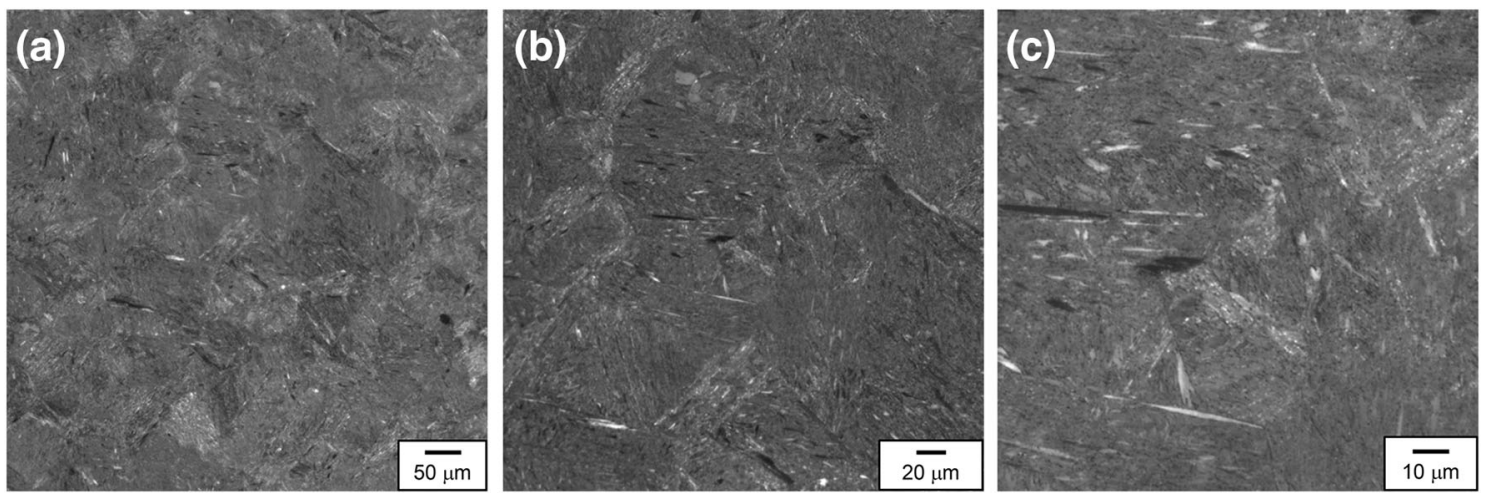

Fig. 3 Polarized light micrographs after immersion etching with $2 \%$ aqueous $\mathrm{FeCl}_{3}$ for $5 \mathrm{~s}$

chemical compositions and microstructures [12]. However, AF9628 steel surface turned completely black after etching in this reagent and nothing was visible on the etched surface. The specimens were back-polished, which revealed the packet structure and not the PAGBs (Fig. 4).

As back-polish is reported to enhance the delineation of PAGBs in many steels etched with different etchants $[5,10,13]$, the AF9628 steel specimens were back-polished after immersion etching with $2 \%$ aqueous $\mathrm{FeCl}_{3}$. However, this did not reveal the PAGBs (Fig. 5). The back-polishing after immersion etching with Vilella's reagent also did not delineate the PAGBs (Fig. 6).
Next, the AF9628 specimens were immersion etched in an ultrasonic cleaner with $100 \mathrm{ml}$ saturated aqueous picric acid and $0.5 \mathrm{~g}$ sodium dodecyl benzene sulfonate (a wetting agent) for $7 \mathrm{~min}$, followed by back-polishing. The results on AF9628 steel were encouraging, as PAGBs were differentiable from the packet and block boundaries (Fig. 7). However, the PAGBs were revealed in a very limited area ( $\sim 10-20$ prior austenite grains) of the specimen. The amount of wetting agent was increased to $1 \mathrm{~g}$ in the etchant and the etching/back-polishing cycle was repeated twice. This also delineated PAGBs in a limited 

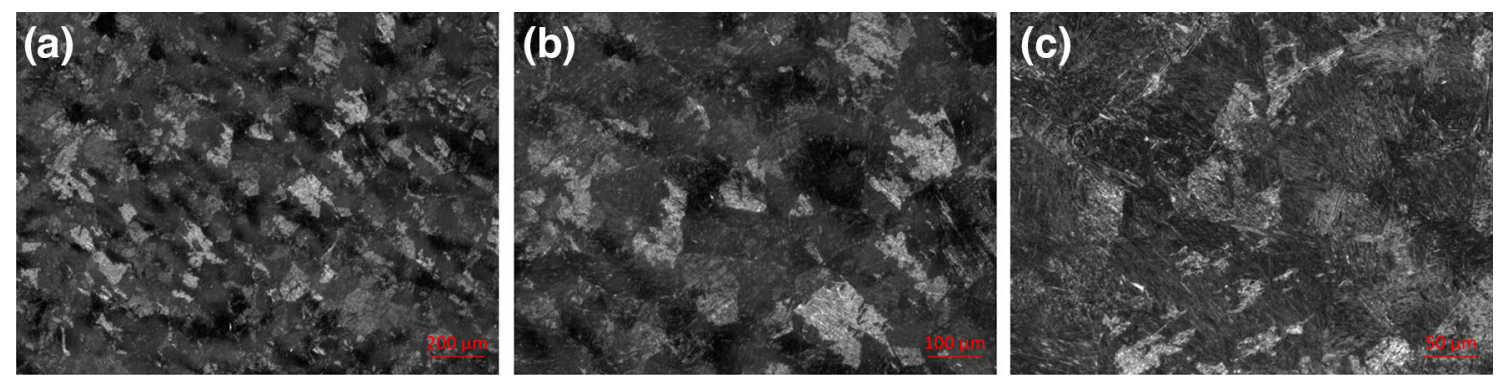

Fig. 4 Polarized light micrographs after immersion etching with $10 \mathrm{~g} \mathrm{CrO}_{3}, 50 \mathrm{~g} \mathrm{NaOH}, 1.5 \mathrm{~g}$ picric acid, and $100 \mathrm{ml}$ distilled water. The etchant was heated to $120^{\circ} \mathrm{C}$ prior to immersion of specimen, and etching was followed by back-polish
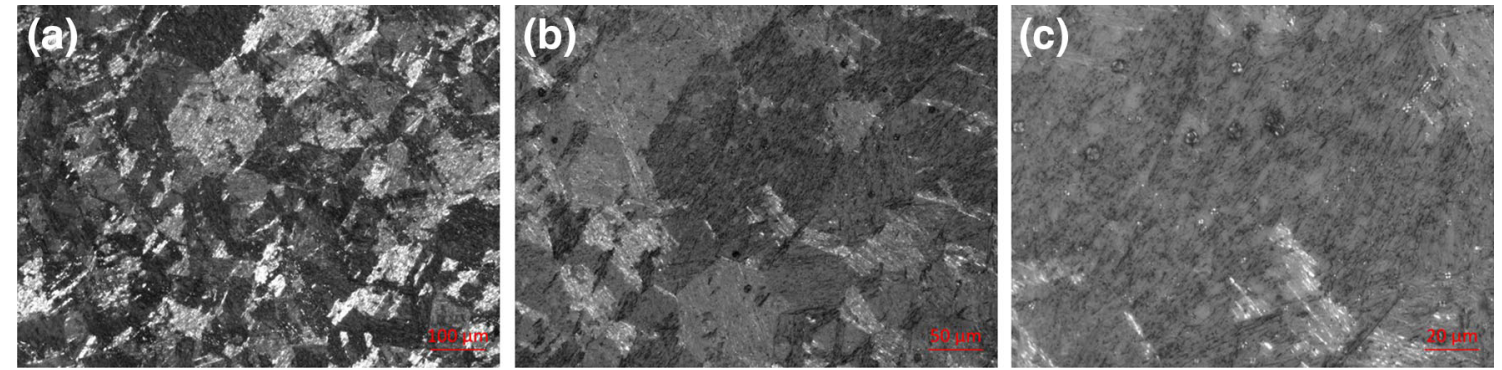

Fig. 5 Polarized light micrographs after immersion etching with $2 \%$ aqueous $\mathrm{FeCl}_{3}$ for $5 \mathrm{~s}$, followed by back-polishing. The etching/backpolishing sequence was repeated for 3 cycles

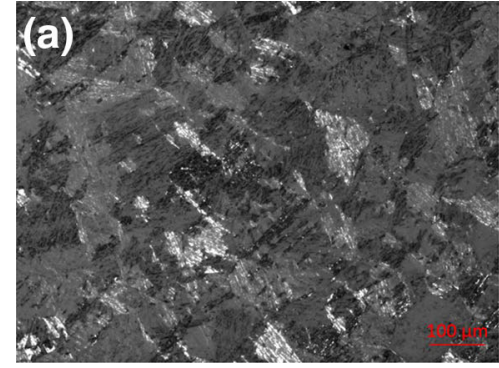

Fig. 6 Polarized light micrographs after immersion etching with Vilella's reagent $(1 \mathrm{~g}$ picric acid, $5 \mathrm{ml} \mathrm{HCl}$, and $100 \mathrm{ml}$ ethanol), followed by back-polishing. The etching/back-polishing sequence

area of specimen (Fig. 8), which is similar to the result for etchant with $0.5 \mathrm{~g}$ wetting agent (Fig. 7).

Since etching of AF9628 steel with the solution comprising saturated aqueous picric acid and a wetting agent had limited success (Figs. 7, 8), a small amount of $\mathrm{HCl}$ was added in this etchant to check if it was more effective in delineating PAGBs in AF9628 steel. First, the specimens were immersion etched in an ultrasonic cleaner with the solution containing $100 \mathrm{ml}$ saturated aqueous picric acid, $0.5 \mathrm{~g}$ sodium dodecyl benzene sulfonate, and $0.3 \mathrm{ml} \mathrm{HCl}$ for $3 \mathrm{~min}$. This etchant appeared to reveal some regions of prior austenite grains (Fig. 9). The etched specimen was lightly back-polished for $15 \mathrm{~s}$ with a goal to better reveal the PAGBs. However, the back-polish removed most of the microstructural features. Thereafter, the specimen was immersion etched in an ultrasonic cleaner with the same

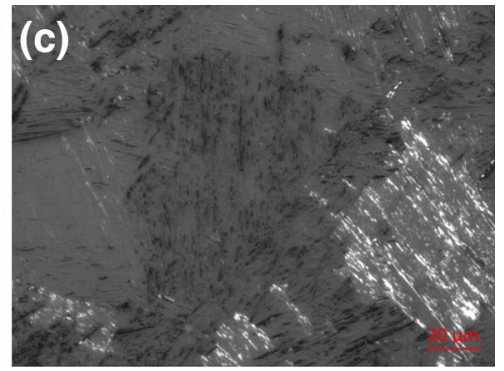

was repeated for 3 cycles. The specimen was immersion etched for $5 \mathrm{~s}$ in the first cycle, and for $10 \mathrm{~s}$ each in the second and third cycles

solution for a longer time of $7 \mathrm{~min}$. After back-polish, PAGBs were delineated in a limited area of specimen (Fig. 10), which is similar to the results described above with the etchant without $\mathrm{HCl}$ (Figs. 7, 8).

Finally, the AF9628 steel specimens were swab etched with a solution of $100 \mathrm{ml}$ saturated aqueous picric acid and $0.5 \mathrm{~g}$ sodium dodecyl benzene sulfonate. The microstructure was not revealed for the etching times of 10,30, and $60 \mathrm{~s}$. However, swab etching with a solution of $100 \mathrm{ml}$ saturated aqueous picric acid and $0.5 \mathrm{~g}$ sodium dodecyl benzene sulfonate for a longer time of 3 min delineated the PAGBs remarkably well (Figs. 11, 12) without requiring any back-polish steps. Swab etching for times longer than $3 \mathrm{~min}$ is likely to etch the intragranular features in addition to the PAGBs, which would make the discernment of PAGBs in the microstructure more difficult. 

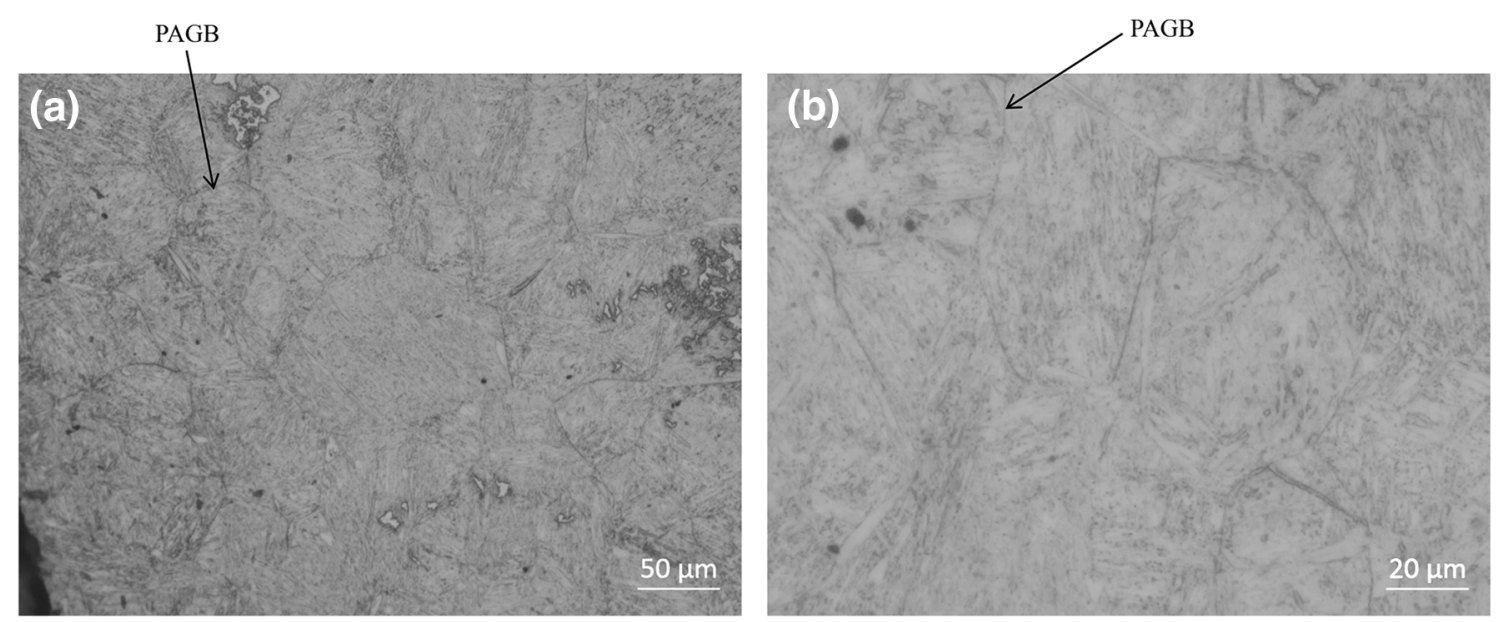

Fig. 7 Optical micrographs after immersion etching with $100 \mathrm{ml}$ saturated aqueous picric acid and $0.5 \mathrm{~g}$ sodium dodecyl benzene sulfonate (a wetting agent) for $7 \mathrm{~min}$, followed by back-polishing

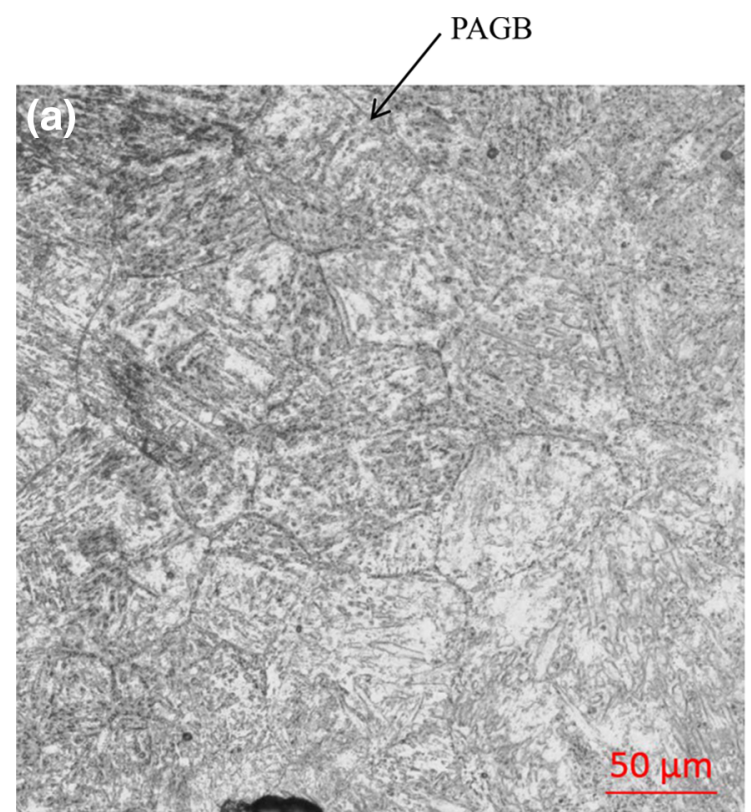

Fig. 8 Optical micrographs after immersion etching with $100 \mathrm{ml}$ saturated aqueous picric acid and $1 \mathrm{~g}$ sodium dodecyl benzene sulfonate (a wetting agent), followed by back-polishing. The etching/

Polarized light microscopy generally provided better images than the bright field optical microscopy, except for specimens etched with a solution of saturated aqueous picric acid (with and without an addition of small amount of $\mathrm{HCl}$ ) and sodium dodecyl benzene sulfonate followed by back-polish. Therefore, either polarized light microscopy or bright field optical microscopy was used to record images depending on the etching methodology employed. The specific optical microscopy technique used to record images is described in the figure captions (Fig. 1, 2, 3, 4, 5, $6,7,8,9,10,11)$.

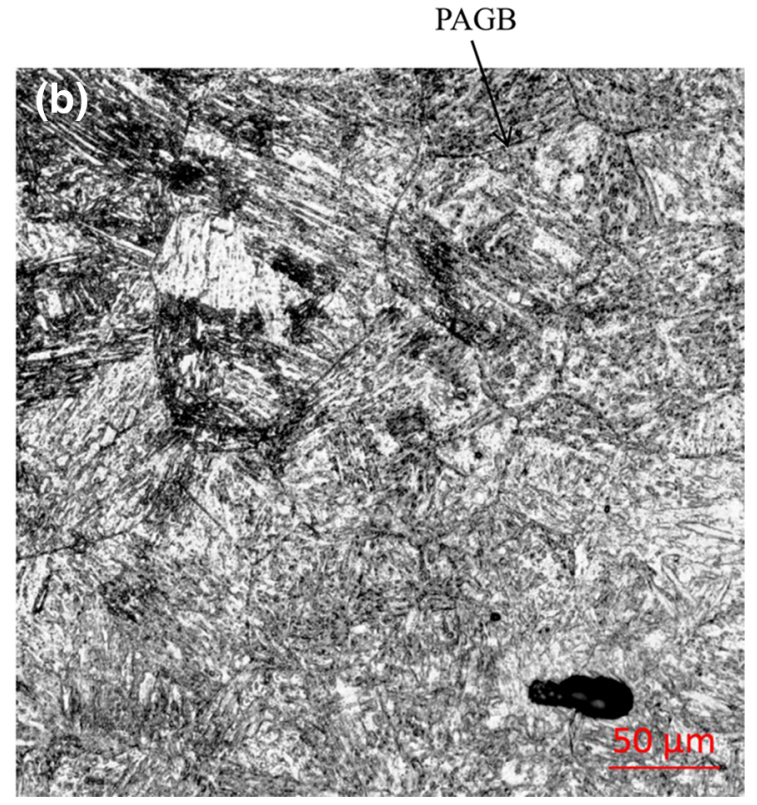

back-polishing sequence was repeated for 2 cycles. The specimen was immersion etched for $5 \mathrm{~min}$ in the first cycle and for $2 \mathrm{~min}$ in the second cycle

\section{Discussion}

The PAGBs in steels can be revealed with numerous techniques, including hot-stage microscopy $[15,16]$, chemical etching $[2,5,10,16]$, oxidation etching [16], and thermal etching [16]. These techniques, when effective, cause the preferential etching of PAGBs while the etching of intragranular microstructural features is suppressed. Chemical etching does not involve an exposure of steel to high temperatures. Therefore, the microstructural state of examined material remains unchanged, when chemical etching is employed to delineate the PAGBs. 

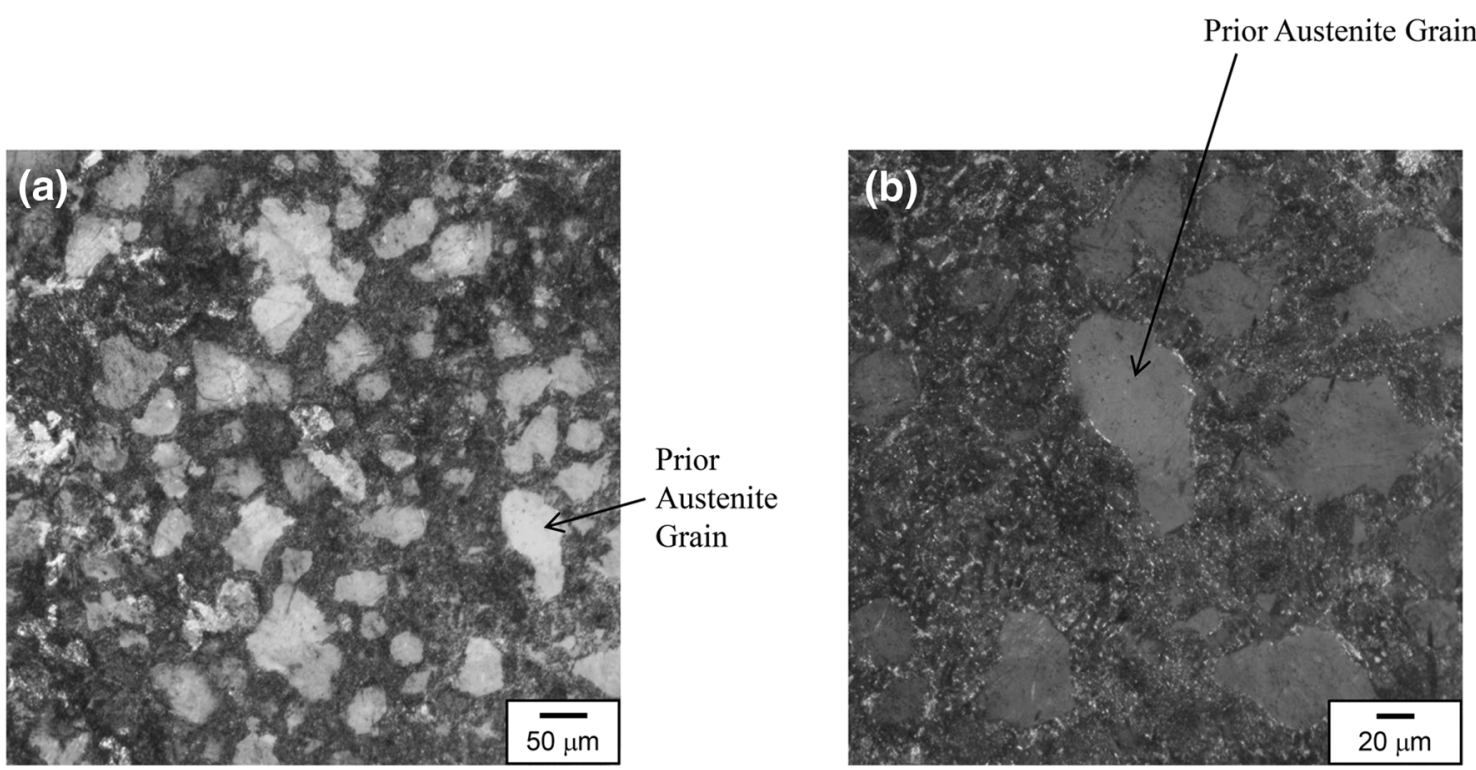

Fig. 9 Polarized light micrographs after immersion etching with $100 \mathrm{ml}$ saturated aqueous picric acid, $0.5 \mathrm{~g}$ sodium dodecyl benzene sulfonate (a wetting agent), and $0.3 \mathrm{ml} \mathrm{HCl}$ for $3 \mathrm{~min}$
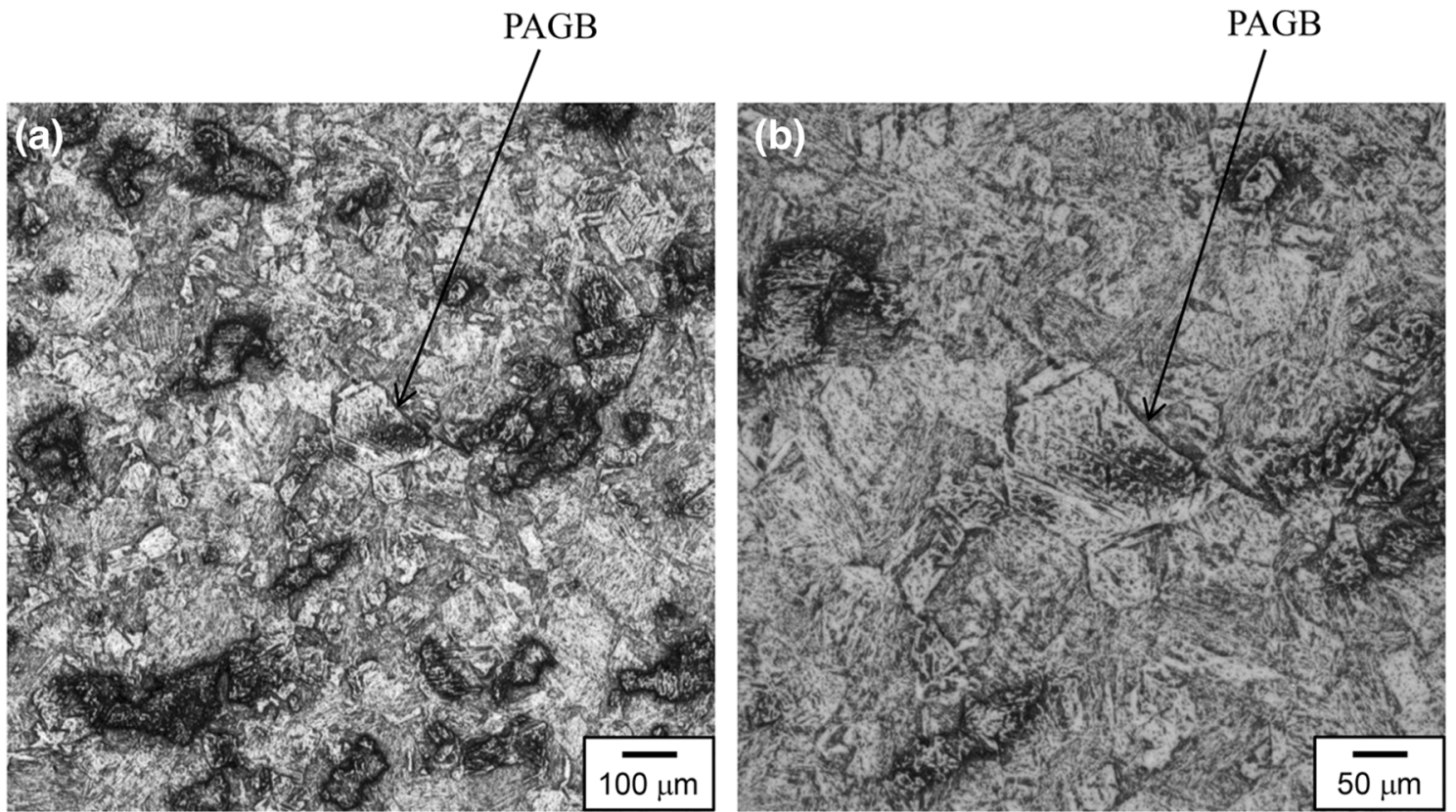

Fig. 10 Optical micrographs after immersion etching with $100 \mathrm{ml}$ saturated aqueous picric acid, $0.5 \mathrm{~g}$ sodium dodecyl benzene sulfonate (a wetting agent), and $0.3 \mathrm{ml} \mathrm{HCl}$ for $7 \mathrm{~min}$, followed by back-polishing

The comparison of Figs. 1, 2, 3, 4, 5 and 6 with Figs. 11 and 12 demonstrates that many of the etchants reported in the literature to be capable of revealing PAGBs are not sufficiently selective for characterizing prior austenite grain size in AF9628. Most of these etchants were effective in revealing the general microstructure, specifically the block and packet structure. The results of current study show that nital clearly revealed the packet structure but not the PAGBs in AF9628 steel (Fig. 1), which is consistent with the results of Swarr and Krauss [2] for a high purity $\mathrm{Fe}-0.2 \mathrm{C}$ alloy. Back-polishing was observed to produce inconsistent results over the surface of the AF9628 specimens. Immersion or swab etching at room temperature without any additional steps that generates uniform results across the surface of a specimen is preferable to an iterative procedure that requires back-polishing or one that requires heating of corrosive solutions. 


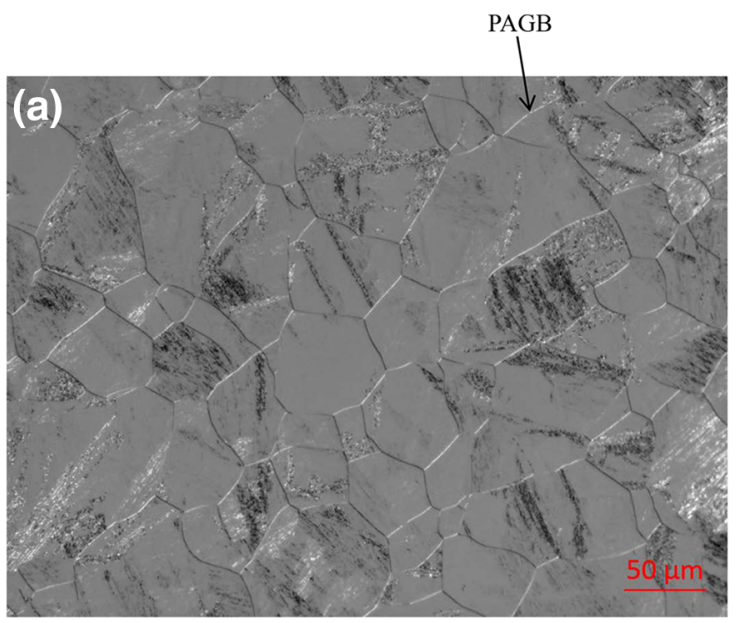

Fig. 11 Polarized light micrographs after swab etching with $100 \mathrm{ml}$ saturated aqueous picric acid and $0.5 \mathrm{~g}$ sodium dodecyl benzene sulfonate (a wetting agent) for $3 \mathrm{~min}$. (a, b) are for the same area on

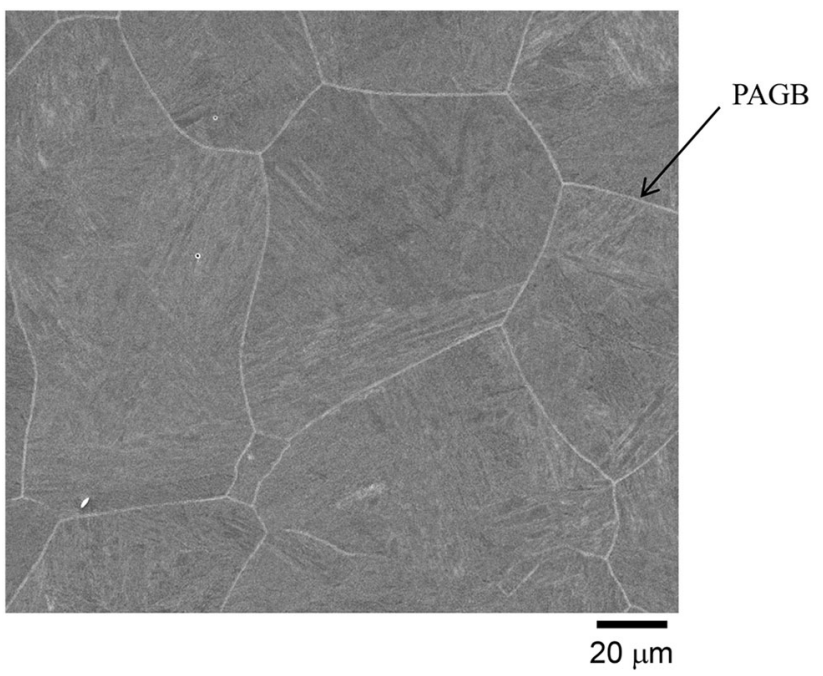

Fig. 12 SEM image after swab etching with $100 \mathrm{ml}$ saturated aqueous picric acid and $0.5 \mathrm{~g}$ sodium dodecyl benzene sulfonate (a wetting agent) for $3 \mathrm{~min}$

Vander Voort reported that in some of the steels (e.g., AISI 4340), which did not respond to the etchant comprising saturated aqueous picric acid and a wetting agent, the following modifications to the procedure were necessary to produce the desired results: (a) an addition of small amount (a few drops to a few $\mathrm{ml}$ per $100 \mathrm{ml}$ of etchant) of $\mathrm{HCl}$; (b) heating the solution to $80-90^{\circ} \mathrm{C}$; and (c) backpolishing [5, 13]. Krauss also reported that etching with an aqueous solution saturated with picric acid and containing a wetting agent with small additions of $\mathrm{HCl}$ was one of the most effective techniques to reveal PAGBs in hardened steels [10]. For AF9628, our results suggest that swab etching (as opposed to immersion in an ultrasonic bath) at

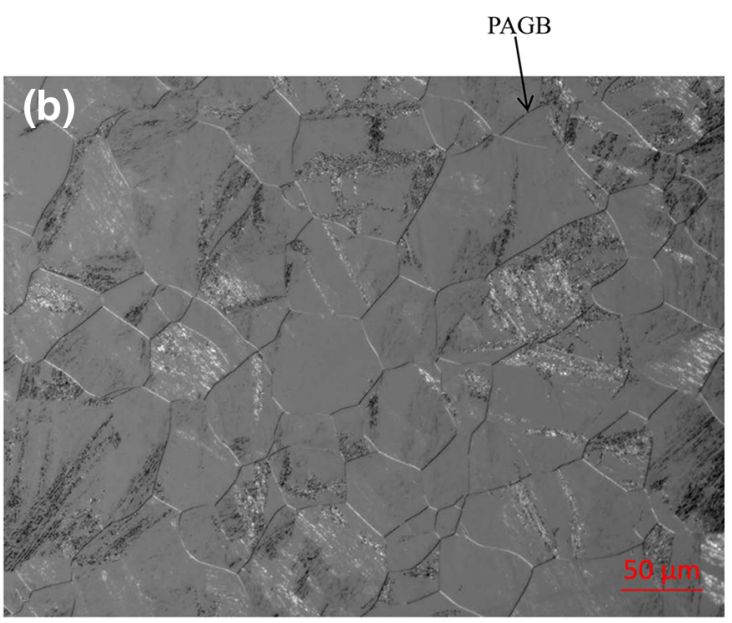

the specimen and are imaged with different analyzer settings. Prior austenite grain boundaries, which are delineated by white lines in (a), are delineated by black lines in (b) and vice versa

room temperature for 2-3 min produces exceptional results.

With a few modifications to the procedures published elsewhere, we found that a variant of the Bechet-Beaujard reagent performed remarkably well on AF9628. This etchant has previously been reported to be ineffective in martensitic and bainitic steels with carbon contents below $\sim 0.3 \%$ or with phosphorus contents below $\sim 0.010 \%$, even when subjected to embrittlement cycles [13]. The carbon content of AF9628 (Table I) puts it approximately on the efficacy boundary previously identified for this etchant. Furthermore, in a steel containing $0.06 \%$ phosphorus, the presence of phosphorus at the PAGBs is reported to promote delineation of PAGBs in the microstructure when the alloy is immersion etched at room temperature in a solution of saturated aqueous picric acid and a wetting agent [17]. The heating of quenched steels in the temper embrittlement range results in the segregation of phosphorus to the PAGBs, which improves the delineation of PAGBs on etching with saturated aqueous picric acid [5, 13]. In the current study, AF9628 steel was investigated in the asquenched (martensitic) condition without being subjected to temper embrittlement. Thus, it comes as a somewhat unexpected result that the best delineation of PAGBs in our study was obtained using a solution of saturated aqueous picric acid and a wetting agent with a procedural modification (i.e., swab etching instead of immersion etching). It is possible that swab etching continuously removes any adherent reaction products from PAGBs in AF9628 steel more effectively than immersion etching even in an ultrasonic cleaner and thereby continually exposes the pristine PAGBs to the etchant, which results in a better delineation of the PAGBs than with the immersion etching technique. 


\section{Conclusions}

The present study was conducted to establish a methodology to delineate PAGBs in AF9628, which is a low-alloy high-performance steel. Several different etchants and etching methods from the literature were investigated. Most methods described in the literature were unsuccessful or had only limited success in revealing PAGBs. However, it was found that swab etching (as opposed to immersion etching) with a solution of $100 \mathrm{ml}$ saturated aqueous picric acid and $0.5 \mathrm{~g}$ sodium dodecyl benzene sulfonate for $3 \mathrm{~min}$ (as opposed to the longer times suggested in a few references) worked remarkably well for delineating the PAGBs in AF9628 steel, even though this alloy is in martensitic condition, contains a low quantity of carbon and has not been heat treated to induce segregation of phosphorus to the PAGBs.

Acknowledgments This research was supported by and performed at the Air Force Research Laboratory, Materials and Manufacturing Directorate, AFRL/RXCM, Wright-Patterson Air Force Base, OH. The authors thank Mr. Tommy Cissel (UES, Inc.) and Mr. Bob Lewis (UES, Inc.) for help with specimen preparations. The authors also thank Mr. George F. Vander Voort and Prof. George Krauss (Colorado School of Mines) for helpful suggestions on etching techniques.

\section{References}

1. J. Hidalgo, M.J. Santofimia, Effect of prior austenite grain size refinement by thermal cycling on the microstructural features of as-quenched lath martensite. Metall. Mater. Trans. A 47A, 5288-5301 (2016)

2. T.E. Swarr, G. Krauss, Boundaries and the strength of low carbon ferrous martensites, in Grain Boundaries in Engineering Materials, ed. by J.L. Walter, J.H. Westbrook, D.A. Woodford (Claitors Publishing Division, Baton Rouge, LA, 1975), pp. $127-138$
3. V.A. Yardley, S. Fahimi, E.J. Payton, Classification of creep crack and cavitation sites in tempered martensite ferritic steel microstructures using MTEX toolbox for EBSD. Mater. Sci. Technol. 31(5), 547-553 (2015). https://doi.org/10.1179/ 1743284714Y.0000000603

4. ASTM E112-13, Standard Test Methods for Determining Average Grain Size, Developed by Subcommittee E04.08 on Grain Size (ASTM International, West Conshohocken, PA, 2013). https://doi.org/10.1520/E0112-13

5. G.F. Vander Voort, Metallography Principles and Practice (McGraw-Hill Inc, New York, NY, 1984), pp. 220-223

6. J.R. Vilella, Metallographic Technique for Steel (American Society for Metals, Cleveland, OH, 1938)

7. D.C. Zipperman, Metallographic Handbook (PACE Technologies, Tucson, AZ, 2011)

8. O.O. Miller, M.J. Day, Ferric chloride etchant for austenite grain size of low-carbon steel. Met. Prog. 56, 692-695 (1949)

9. C.A. Johnson, Metallography Principles and Procedures (LECO Corporation, St. Joseph, MI, 1996)

10. G. Krauss, STEELS Processing, Structure, and Performance (ASM International, Materials Park, OH, 2005), pp. 121-123

11. S. Bechet, L. Beaujard, New reagent for the micrographical demonstration of the austenite grain of hardened or hardenedtempered steels. Rev. Met. 52, 830-836 (1955)

12. L. Zhang, D.C. Guo, A general etchant for revealing prioraustenite grain boundaries in steels. Mater. Charact. 30, 299-305 (1993)

13. G.F. Vander Voort, Revealing prior austenite grain boundaries in heat treated steels. http://www.georgevandervoort.com/metallo graphy/specific/iron-and-steel-specific/20001306-revealing-prioraustenite-grain-boundaries-in-heat-treated-steels-article.html. Accessed 01 December 2016

14. Low alloy high performance steel, United States Patent Application Publication, US 2016/0369362 A1

15. A. Ray, S.K. Ray, S.R. Mediratta, Effect of carbides on the austenite grain growth characteristics in $1 \mathrm{Cr}-1 \mathrm{C}$ and $6 \mathrm{Cr}-1 \mathrm{Mo}-1 \mathrm{C}$ steels. J. Mater. Sci. 25, 5070-5076 (1990)

16. C. García de Andrés, M.J. Bartolomé, C. Capdevila, D. San Martín, F.G. Caballero, V. López, Metallographic techniques for the determination of the austenite grain size in medium-carbon microalloyed steels. Mater. Charact. 46, 389-398 (2001)

17. A.H. Ücisik, H.C. Feng, C.J. McMahon, The influence of intercritical heat treatment on the temper embrittlement of a P-Doped Ni-Cr Steel. Metall. Trans. 9A, 321-329 (1978) 